\title{
Stereospecific Polymerizations of Methacrylic Esters Having Hetero Atoms in Their Pendant Alkyl Groups
}

\author{
Takashi Ito, * Kazuyoshi Aoshima, ${ }^{* *}$ Fujio Toda, \\ Keikichi Uno, and Yoshio IwakURA \\ Department of Synthetic Chemistry, Faculty of Engineering, \\ University of Tokyo, Bunkyo-ku, Tokyo, Japan.
}

(Received August 8, 1969)

\begin{abstract}
Various methacrylic esters with and without hetero atoms in their pendant ester groups were polymerized in toluene or in THF at $-78^{\circ} \mathrm{C}$ using $n$-BuLi $\mathrm{LiAlH}_{4}$, or $i-\mathrm{BuMgBr}$ as an initiator. By comparing the isotacticities of the resultant polymers using the NMR spectral method, the influence of the hetero atom in the pendant ester group of the monomer on polymer stereoregularity was clarified. The experiments showed that the isotacticities of those polymers containing nitrogen or oxygen atoms in their side chains were lower than the isotacticites of those not containing such atoms. On the basis of these results the assumption was made that such depressing effects in isotactic propagation were caused by Lewis basicity of the nitrogen or oxygen atoms in the pendant ester groups. Furthermore, the effect of THF added to the polymerization reaction mixture, the effects of monomer concentration, the number of carbon atoms between the hetero atom and ester oxygen, and of the counter cation, all substantiated this assumption. The effect of hetero atoms on the syndiotacticities of the resultant polymers was also briefly studied.
\end{abstract}

KEY WORDS Stereospecific Polymerization / Methacrylic Ester / Hetero Atom/Stereoregularity/NMR/Lewis Base/Pendant Group/

In a series of studies on the reaction of poly(glycidyl methacrylate) (poly(GMA)) with amine, the hydroxy group produced by the reaction was found to catalyze the reaction of vicinal epoxy groups. ${ }^{1}$ This fact suggested that the reaction of poly(GMA) with amine would be affected by the tacticity of poly(GMA), and the synthesis of stereospecific poly(GMA) was examined..$^{2,3}$ During the examination of synthesizing stereospecific poly(GMA), it was found that the oxygen atom of the epoxy ring affected the tacticity of the polymer produced by anionic polymerization. ${ }^{3}$

From the considerable amount of study made on the synthesis of highly isotactic polymethacrylate, some information has been made

* Correspondence should be addressed to this author at the Research Laboratory of Resources Utilization, Tokyo Institute of Technology, Ookayama, Meguro-ku, Tokyo.

** Present address: Taketoyo-Factory, Nippon Oils and Fats Co. Ltd., Taketoyo, Chita-gun, Aichi, Japan. available on anionic stereospecific polymerization of various methacrylic esters, with special reference to the steric effects of pendant alkyl groups. $^{4,5}$ However, little is known about the influence of hetero atoms in the alkyl group of methacrylate on the polymerization reaction. In this paper, the effect of hetero atoms on polymer tacticities is examined and the stereospecificity of the polymer was found to be depressed appreciably with the introduction of an oxygen or nitrogen atom in the pendant ester group.

Concerning the mechanism of the sterically controlled anionic propagation reaction of methyl methacrylate in nonpolar solvent using lithium alkyl as an initiator, many reports have been made, for instance, by Cram et al., ${ }^{6}$ Bawn et al. ${ }^{7}$ Goode et al., ${ }^{8}$ Glusker et al., ${ }^{9}$ and Furukawa. ${ }^{10}$ It seems quite probable from these mechanisms that the coordination of the counter cation, i.e., $\mathrm{Li}^{+}$, to carbonyl groups of the last and penultimate monomer units of a propagating chain is essential for isotactic propagation (Figure 1 a). 
Stereospecific Polymerizations of Methacrylates

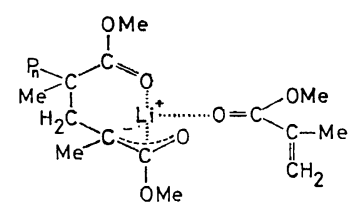

(a)

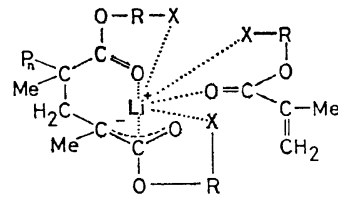

(b)

Figure 1. Schematic representations of the growing chain end in the stereospecific polymerization of methyl methacrylate (a) and of methacrylic ester having an $\mathrm{N}$ or $\mathrm{O}$ atom in the pendant ester group (b) by alkyl lithium. $\mathrm{P}_{n}, \mathrm{Me}$, and $\mathrm{R}$ refer to the growing polymer chain, methyl group, and alkyl group, respectively. $\mathrm{X}$ denotes the hetero atom.

Poly(methyl methacrylate) with purely isotactic configuration has been synthesized by using lithium aluminum hydride ${ }^{4}$ or certain Grignard reagents ${ }^{11}$ as initiators. The mechanisms proposed for these stereospecific polymerizations, though they are not clear enough, are similar to those proposed for polymerization initiated by lithium alkyl.

From the results of our experiments, we have tentatively concluded the role of the hetero atom in the pendant ester group to be as follows. Some hetero atoms may contribute to a weakening of the coordination of the counter cation to any of the carbonyl groups of the ultimate or penultimate monomer unit or of the monomer itself, as a result of the participation of the hetero atom in the coordination. (Figure $1 \mathrm{~b}$ ). When the electron-donating ability of $\mathrm{X}$ is sufficiently high, the contribution of $\mathrm{X}$ to depressing isotactic propagation may be increased. Furthermore, the syndiotactic propagation which is expected in polymerizations at low temperatures in such polar mediums as tetrahydrofuran (THF) may be affected by the presence of an hetero atom in the pendant ester group.

\section{RESULTS}

In order to study the influence of the hetero atom introduced into the monomer on the stereospecificity of the anionically initiated propagation reaction, twelve methacrylate monomers were prepared: 2-methoxyethyl methacrylate (MOMA), $\quad \mathrm{CH}_{2}=\mathrm{C}\left(\mathrm{CH}_{3}\right) \mathrm{CO}_{2} \mathrm{CH}_{2} \mathrm{CH}_{2} \mathrm{OCH}_{3} ;$ 2methylthioethyl methacrylate (MTMA), $\mathrm{CH}_{2}=$ $\mathrm{C}\left(\mathrm{CH}_{3}\right) \mathrm{CO}_{2} \mathrm{CH}_{2} \mathrm{CH}_{2} \mathrm{SCH}_{3} ; \mathrm{N}$, N-dimethylaminoethyl methacrylate (MAMA), $\mathrm{CH}_{2}=\mathrm{C}\left(\mathrm{CH}_{3}\right) \mathrm{CO}_{2}$ -
$\mathrm{CH}_{2} \mathrm{CH}_{2} \mathrm{~N}\left(\mathrm{CH}_{3}\right)_{2}$; glycidyl methacrylate (GMA), $\mathrm{CH}_{2}=\mathrm{C}\left(\mathrm{CH}_{3}\right) \mathrm{CO}_{2} \mathrm{CH}_{2} \mathrm{CH}-\mathrm{CH}_{2} ; 2$, 3-epithiopropyl $\mathrm{O}^{\prime}$

methacrylate (ETMA), $\quad \mathrm{CH}_{2}=\mathrm{C}\left(\mathrm{CH}_{3}\right) \mathrm{CO}_{2} \mathrm{CH}_{2}$ $\mathrm{CH}-\mathrm{CH}_{2}$; tetrahydrofurfuryl methacrylate 'S'

(THFMA), $\mathrm{CH}_{2}=\mathrm{C}\left(\mathrm{CH}_{3}\right) \mathrm{CO}_{2} \mathrm{CH}_{2}-{ }_{\mathrm{O}} ;$ furfuryl methacrylate (FMA), $\mathrm{CH}_{2}=\mathrm{C}\left(\mathrm{CH}_{3}\right) \mathrm{CO}_{2} \mathrm{CH}_{2}-\mathrm{O}^{\prime}$; 2-pyridylmethyl methacrylate (PMMA), $\mathrm{CH}_{2}=$ $\mathrm{C}\left(\mathrm{CH}_{3}\right) \mathrm{CO}_{2} \mathrm{CH}_{2}-\mathrm{N} ;$ 3-methoxypropyl methacrylate (MPMA), $\mathrm{CH}_{2}=\mathrm{C}\left(\mathrm{CH}_{3}\right) \mathrm{CO}_{2}\left(\mathrm{CH}_{2}\right)_{3} \mathrm{OCH}_{3}$; 4-methoxybutyl methacrylate (MBMA), $\mathrm{CH}_{2}=$ $\mathrm{C}\left(\mathrm{CH}_{3}\right) \mathrm{CO}_{2}\left(\mathrm{CH}_{2}\right)_{4} \mathrm{OCH}_{3}$; cyclopropylmethyl methacrylate (CPrMA), $\mathrm{CH}_{2}=\mathrm{C}\left(\mathrm{CH}_{3}\right) \mathrm{CO}_{2} \mathrm{CH}_{2} \mathrm{CH}-\mathrm{CH}_{2}$; $\mathrm{CH}_{2}$ cyclopentylmethyl methacrylate (CPeMA) $\mathrm{CH}_{2}=$ $\mathrm{C}\left(\mathrm{CH}_{3}\right) \mathrm{CO}_{2} \mathrm{CH}_{2}-\square$.

Most of these monomers were prepared by condensation reactions between methacryloyl chloride and corresponding alcohols. Ester exchange reactions between methyl methacrylate and corresponding alcohols were also used for the syntheses of some monomers. The latter method was found to be more useful for the synthesis of THFMA because of the difficulty in separating the product from the by-product methacrylic anhydride.

The polymerization reactions were carried out in toluene or in THF at $-78^{\circ} \mathrm{C}$ in vacuo using $n$-butyllithium $(n$-BuLi), lithium aluminum hydride $\left(\mathrm{LiAlH}_{4}\right)$, iso-butylmagnesium bromide (i- 
T. Ito, K. Aoshima, F. Toda, K. Uno, and Y. Iwakura

Table I. Polymerizations of various methacrylates ${ }^{a}$

\begin{tabular}{|c|c|c|c|c|c|c|c|c|c|}
\hline $\begin{array}{l}\text { Run } \\
\text { No. }\end{array}$ & Solvent ${ }^{b}$ & Initiator $^{\mathrm{c}}$ & $\underset{(\mathrm{hr})}{\text { Time }}$ & $\begin{array}{l}\text { Con- } \\
\text { version } \\
(\%)\end{array}$ & $\begin{array}{l}\text { Run } \\
\text { No. }\end{array}$ & Solvent $t^{b}$ & Initiator ${ }^{\mathrm{c}}$ & $\underset{(\mathrm{hr})}{\operatorname{Time}}$ & $\begin{array}{l}\text { Con- } \\
\text { version } \\
(\%)\end{array}$ \\
\hline \multicolumn{5}{|c|}{ 2-Methoxyethyl methacrylate (MOMA) } & \multicolumn{5}{|c|}{ Tetrahydrofurfuryl methacrylate (THFMA) } \\
\hline 1 & Toluene & $n$-BuLi & 98 & 35 & 27 & Toluene & $n$-BuLi & 35 & 60 \\
\hline 2 & Toluene & $\mathrm{LiAlH}_{4}$ & 98 & 65 & 28 & Toluene & $\mathrm{LiAlH}_{4}$ & 168 & 45 \\
\hline 3 & Toluene & $i-\mathrm{BuMgBr}$ & 98 & 35 & 29 & Toluene & $i$-BuMgBr & 35 & 15 \\
\hline 4 & Toluene & $\mathrm{SrZnEt}_{4}$ & 41 & 85 & 30 & $\mathrm{THF}$ & $\mathrm{LiAlH}_{4}$ & 35 & 10 \\
\hline 5 & THF & $\mathrm{LiAlH}_{4}$ & 196 & 50 & 31 & THF & $i$-BuMgBr & 19 & 45 \\
\hline \multicolumn{5}{|c|}{ 2-Methylthioethyl methacrylate (MTMA) } & \multicolumn{5}{|c|}{ Furfuryl methacrylate (FMA) } \\
\hline 6 & Toluene & n-BuLi & 98 & 35 & 32 & Toluene & $n$-BuLi & 82 & 65 \\
\hline 7 & Toluene & $\mathrm{LiAlH}_{4}$ & 276 & 45 & 33 & Toluene & $\mathrm{LiAlH}_{4}$ & 0.5 & 60 \\
\hline 8 & Toluene & $i$-BuMgBr & 92 & 50 & 34 & Toluene & $i$-BuMgBr & 82 & 15 \\
\hline 9 & THF & $\mathrm{LiAlH}_{4}$ & 92 & 60 & 35 & THF & $\mathrm{LiAlH}_{4}$ & 44 & 95 \\
\hline 10 & THF & $i$-BuMgBr & 195 & 65 & \multicolumn{5}{|c|}{ 2-Pyridylmethyl methacrylate (PMMA) } \\
\hline \multicolumn{5}{|c|}{ N, N-Dimethylaminoethyl methacrylate (MAMA) } & 36 & Toluene & $n$-BuLi & 41 & 35 \\
\hline 11 & Toluene & $n-\mathrm{BuLi}$ & 35 & 30 & 37 & Toluene & $\mathrm{LiAlH}_{4}$ & 41 & 40 \\
\hline 12 & Toluene & $\mathrm{LiAlH}_{4}$ & 14 & 40 & 38 & Toluene & $i$-BuMgBr & 41 & 15 \\
\hline 13 & Toluene & $i$-BuMgBr & 35 & 25 & \multicolumn{5}{|c|}{ 3-Methoxypropyl methacrylate (MPMA) } \\
\hline 14 & $\mathrm{THF}$ & $\mathrm{LiAlH}_{4}$ & 26 & 75 & 39 & Toluene & $n$-BuLi & 20 & 60 \\
\hline \multicolumn{5}{|c|}{ Glycidyl methacrylate (GMA) } & 40 & Toluene & $\mathrm{LiAlH}_{4}$ & 85 & 80 \\
\hline 15 & Toluene & n-BuLi & 39 & 30 & 41 & Toluene & $i$-BuMgBr & 20 & 70 \\
\hline 16 & Toluene & $\mathrm{LiAlH}_{4}$ & 42 & 40 & \multicolumn{5}{|c|}{ 4-Methoxybutyl methacrylate (MBMA) } \\
\hline 17 & Toluene & $i$-BuMgBr & 58 & 30 & 42 & Toluene & $n$-BuLi & 43 & 65 \\
\hline 18 & Toluene & $\mathrm{SrZnEt}_{4}$ & 39 & 40 & 43 & Toluene & $\mathrm{LiAlH}_{4}$ & 1 & 85 \\
\hline 19 & THF & $\mathrm{LiAlH}_{4}$ & 42 & 56 & 44 & Toluene & $i$-BuMgBr & 18 & 64 \\
\hline 20 & $\mathrm{THF}$ & $i$-BuMgBr & 58 & 90 & \multicolumn{5}{|c|}{ Cyclopropylmethyl methacrylate (CPrMA) } \\
\hline \multicolumn{5}{|c|}{ 2,3-Epithiopropyl methacrylate (ETMA) } & 45 & Toluene & $n$-BuLi & 102 & 40 \\
\hline 21 & Toluene & $n$-BuLi & 2.5 & 80 & 46 & Toluene & $\mathrm{LiAlH}_{4}$ & 42 & 9 \\
\hline 22 & Toluene & $\mathrm{LiAlH}_{4}$ & 7 & 45 & 47 & Toluene & $i$-BuMgBr & 58 & 72 \\
\hline 23 & Toluene & $i$-BuMgBr & 31 & 90 & 48 & THF & $\mathrm{LiAlH}_{4}$ & 42 & 8 \\
\hline 24 & Toluene & $\mathrm{SrZnEt}_{4}$ & 0.3 & 80 & 49 & THF & $i$-BuMgBr & 58 & 81 \\
\hline 25 & THF & $\mathrm{LiAlH}_{4}$ & 58 & 40 & \multicolumn{5}{|c|}{ Cyclopentylmethyl methacrylate (CPeMA) } \\
\hline \multirow[t]{2}{*}{26} & THF & $i$-BuMgBr & 60 & 100 & 50 & Toluene & $n$-BuLi & 20 & 75 \\
\hline & & & & & 51 & Toluene & $\mathrm{LiAlH}_{4}$ & 1 & 75 \\
\hline
\end{tabular}

a Polymerization temperature, $-78^{\circ} \mathrm{C}$.

b Monomer/solvent, $2 \mathrm{~m} l / 5 \mathrm{~m} l$.

c Concentration of initiator (mol \% to monomer), 4-10 ( $n$-BuLi); $1-6\left(\mathrm{LiAlH}_{4}\right) ; 2-14(i-\mathrm{BuMgBr})$; $4\left(\mathrm{SrZnEt}_{4}\right)$.

$\mathrm{BuMgBr}$ ), and in some cases, strontium zinc tetraethyl $^{5}$ as an initiator. The results of the polymerization of each monomer are shown in Table I*.

* More detailed data on the polymerizations of GMA, ETMA, and CPrMA were provided in the preceding communication. ${ }^{3}$
Anionic polymerizations of GMA and ETMA were found, by observation of the infrared and NMR spectra of the polymers obtained, to proceed through the vinyl group only, in spite of the sensitivity of the epoxy and epithio groups in the monomers to an anion ( $c f$. ref. 3 and Figure 2). 


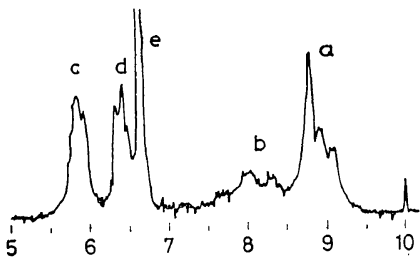

Poly (MOMA)

$\mathrm{R}=-\stackrel{(d)}{\mathrm{CH}_{2}} \stackrel{(\mathrm{O}}{\mathrm{OCH}_{3}}$

Run No. 3
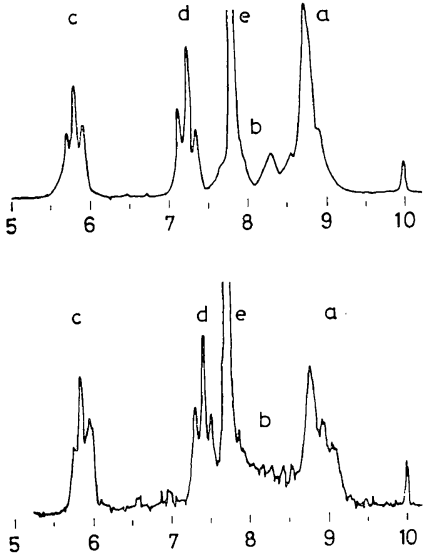

(1)
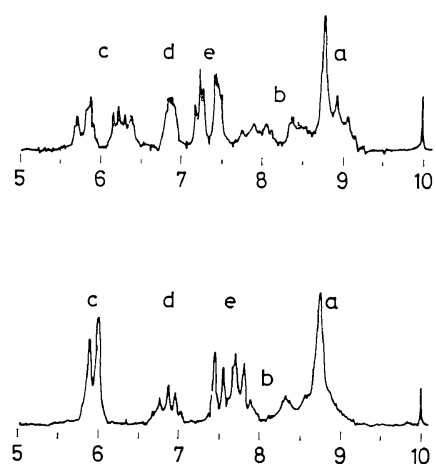

Poly(ETMA)

$R=-\stackrel{(d)}{C}+(e)$

Run No. 22

Poly (GMA)

$\mathrm{R}=-\stackrel{(d)}{\mathrm{C}} \mathrm{O}_{0}-\mathrm{CH}_{2}$

Run No. 16

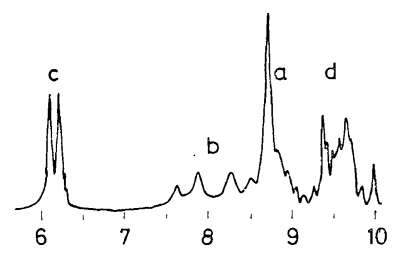

Poly (CPrMA)

$R=\langle(d)$

Run No. 46

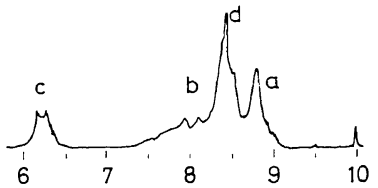

Poly(CPeMA)

Poly (THFMA)

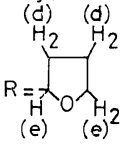

Run No. 28
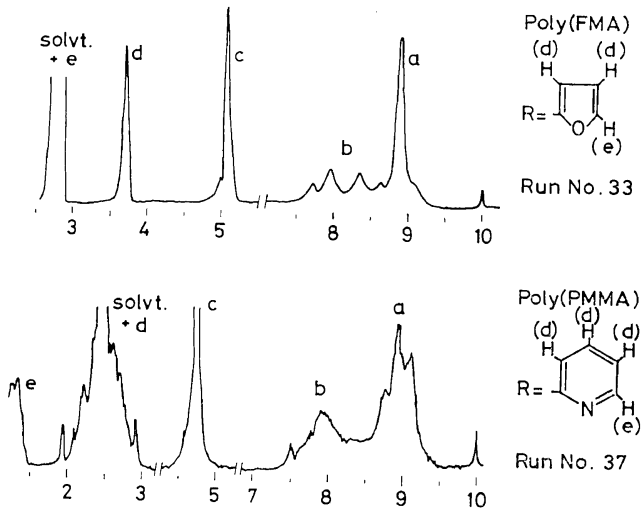

Poly(MPMA)

$\mathrm{R}=-\stackrel{(\mathrm{d})}{\mathrm{CH}_{2}} \mathrm{CH}_{2} \mathrm{OCH}_{3}$

Run No. 40

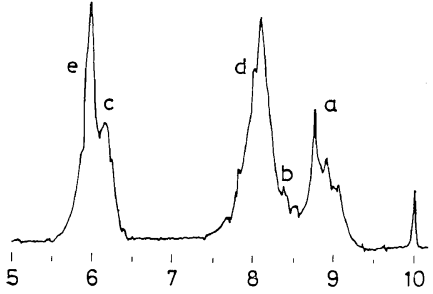

(2)

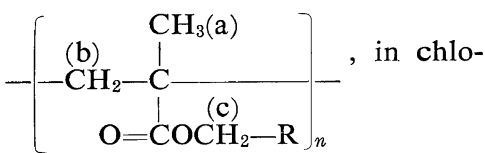

roform solution at $60^{\circ} \mathrm{C}, 60 \mathrm{MC}(100 \mathrm{MC}$ spectrum is presented for poly (GMA)). Chemical shifts are shown in $\tau$ value and peaks at $\tau 10.0$ are due to tetramethylsilane as the internal standard. The spectrum of poly (MBMA) is omitted because the figure is very close to that of poly (MPMA). (a), (b),$\ldots$, (f) correspond to the assignment of each peak which is shown in the figure. Run No. corresponds to that cited in Tables I and II.

Polymer J., Vol. 1, No. 3, 1970 
T. Ito, K. Aoshima, F. Toda, K. Uno, and Y. Iwakura

Table II. Tacticities of polymers

\begin{tabular}{|c|c|c|c|c|c|c|c|c|c|c|c|c|c|c|c|}
\hline \multirow{2}{*}{$\begin{array}{l}\text { Run } \\
\text { No. }{ }^{a}\end{array}$} & \multirow{2}{*}{ Initiator } & $1 \%$ & $H \%$ & $S \%$ & $1 \%$ & $H \%$ & $S \%$ & \multirow{2}{*}{$\begin{array}{l}\text { Run } \\
\text { No. }^{a}\end{array}$} & \multirow{2}{*}{ Initiator } & \multirow{2}{*}{\multicolumn{3}{|c|}{$\frac{I \% H \% S \%}{\text { Toluene }^{b}}$}} & \multicolumn{3}{|c|}{$I \% H \% S \%$} \\
\hline & & \multicolumn{3}{|c|}{ Toluene ${ }^{b}$} & \multicolumn{3}{|c|}{$\mathrm{THF}^{\mathrm{b}}$} & & & & & & \multicolumn{3}{|c|}{$\mathrm{THF}^{\mathrm{b}}$} \\
\hline \multicolumn{8}{|c|}{ Poly(2-methoxyethyl methacrylate) } & 28,30 & $\mathrm{LiAlH}_{4}$ & 72 & 15 & 13 & 1 & 18 & 81 \\
\hline 1 & $n$-BuLi & & 4 & 66 & & & & 29,31 & $i$-BuMgBr & 7 & 42 & 51 & 2 & 15 & 83 \\
\hline 2,5 & $\mathrm{LiAlH}_{4}$ & 39 & 33 & 38 & 9 & 13 & 78 & \multicolumn{8}{|c|}{ Poly(furfuryl methacrylate) } \\
\hline 3 & $i$-BuMgBr & 80 & 8 & 12 & & & & 32 & $n$-BuLi & 86 & 11 & 3 & & & \\
\hline 4 & $\mathrm{SrZnEt}_{4}$ & 78 & 14 & 8 & & & & 33,35 & $\mathrm{LiAlH}_{4}$ & 100 & 0 & 0 & 0 & 10 & 90 \\
\hline \multicolumn{8}{|c|}{ Poly(2-methylthioethyl methacaylate) } & 34 & $i$-BuMgBr & 97 & \multicolumn{2}{|c|}{3} & & & \\
\hline 6 & n-BuLi & 96 & \multicolumn{2}{|c|}{4} & & & & \multicolumn{8}{|c|}{ Poly(2-pyridylmethyl methacrylate) } \\
\hline 7,9 & $\mathrm{LiAlH}_{4}$ & 97 & 3 & 0 & 3 & 11 & 86 & 36 & $n$-BuLi & 10 & 51 & 39 & & & \\
\hline 8,10 & $i$-BuMgBr & 98 & & 2 & 5 & 3 & 92 & 37 & $\mathrm{LiAlH}_{4}$ & 7 & 52 & 41 & & & \\
\hline \multicolumn{8}{|c|}{ Poly(N, N-dimethylaminoethyl methacrylate) } & 38 & $i$-BuMgBr & 4 & 43 & 53 & & & \\
\hline 11 & $n$-BuLi & 73 & 16 & 11 & & & & \multicolumn{8}{|c|}{ Poly(3-methoxypropyl methacrylate) } \\
\hline 12,14 & $\mathrm{LiAlH}_{4}$ & 81 & 9 & 10 & 2 & 2 & 96 & 39 & $n-\mathrm{BuLi}$ & 27 & 38 & 35 & & & \\
\hline 13 & $i$-BuMgBr & 4 & 15 & 81 & & & & 40 & $\mathrm{LiAlH}_{4}$ & 87 & 9 & 4 & & & \\
\hline \multicolumn{8}{|c|}{ Poly(glycidyl methacrylate) } & 41 & $i$-BuMgBr & 100 & 0 & 0 & & & \\
\hline 15 & $n$-BuLi & 33 & 38 & 29 & & & & \multicolumn{8}{|c|}{ Poly(4-methoxybutyl methacrylate) } \\
\hline 16,19 & $\mathrm{LiAlH}_{4}$ & 80 & 15 & 5 & 3 & 44 & 53 & 42 & $n$-BuLi & 59 & 22 & 19 & & & \\
\hline 17,20 & $i$ - $\mathrm{BuMgBr}$ & 26 & 44 & 33 & 4 & 42 & 54 & 43 & $\mathrm{LiAlH}_{4}$ & 90 & 10 & 0 & & & \\
\hline 18 & $\mathrm{SrZnEt}_{4}$ & 50 & 41 & 9 & & & & 44 & $i$-BuMgBr & 100 & 0 & 0 & & & \\
\hline \multicolumn{8}{|c|}{ Poly(2,3-epithiopropyl methacrylate) } & \multicolumn{8}{|c|}{ Poly(cyclopropylmethyl methacrylate) } \\
\hline 21 & n-BuLi & 95 & 2 & 3 & & & & 45 & n-BuLi & 92 & 4 & 4 & & & \\
\hline 22,25 & $\mathrm{LiAlH}_{4}$ & 100 & 0 & 0 & 0 & 13 & 87 & 46,48 & $\mathrm{LiAlH}_{4}$ & 94 & 3 & 3 & 0 & 47 & 53 \\
\hline 23,26 & $i$-BuMgBr & 95 & 3 & 2 & 0 & 7 & 93 & 47,49 & $i$-BuMgBr & 96 & 2 & 2 & 2 & 10 & 88 \\
\hline 24 & $\mathrm{SrZnEt}_{4}$ & 84 & 16 & 0 & & & & \multicolumn{8}{|c|}{ Poly(cyclopentylmethyl methacrylate) } \\
\hline \multicolumn{8}{|c|}{ Poly(tetrahydrofurfuryl methacrylate) } & 50 & $n-\mathrm{BuLi}$ & 100 & 0 & 0 & 100 & 0 & $0^{\mathrm{c}}$ \\
\hline 27 & $n$-BuLi & 4 & 46 & 50 & & & & 51 & $\mathrm{LiAlH}_{4}$ & 100 & 0 & 0 & 100 & 0 & $0^{\mathrm{c}}$ \\
\hline
\end{tabular}

a Run numbers are equivalent to those of Table I. Two numbers in a line, e.g., 2,5, correspond to "Toluene" and "THF" respectively.

b "Toluene" and "THF" mean the solvents in which the polymerization reactions were carried out.

c Polymerization in toluene in the presence of an equimolar amount of THF to the monomer (see text).

Table III. Polymerizations of glycidyl methacrylate in toluene initiated by $\mathrm{LiAlH}_{4}$ at various monomer concentrations ${ }^{\mathrm{a}}$

\begin{tabular}{cccccccc}
\hline $\begin{array}{c}\text { Run } \\
\text { No. }\end{array}$ & $\begin{array}{c}\text { Toluene/ } \\
\text { monomer }\end{array}$ & $\begin{array}{c}\text { Concentration of } \\
\text { initiator }^{\mathrm{c}}\end{array}$ & $\begin{array}{c}\text { Time } \\
(\mathrm{hr})\end{array}$ & $\begin{array}{c}\text { Conversion } \\
(\%)\end{array}$ & \multicolumn{3}{c}{ Tacticity $(\%)$} \\
\hline 52 & 1.0 & 5 & 45 & 5 & 74 & 19 & 7 \\
16 & 2.5 & 5 & 42 & 40 & 80 & 15 & 5 \\
53 & 5.0 & 5 & 45 & 10 & 84 & 8 & 8 \\
54 & 10.0 & 5 & 45 & 10 & 80 & 13 & 7 \\
55 & 20.0 & 30 & 85 & 7 & 84 & 9 & 7 \\
56 & 37.5 & 21 & 85 & trace & 84 & 10 & 6 \\
57 & 100.0 & 40 & trace & 86 & 7 & 7 \\
\hline
\end{tabular}

a Polymerization temperature, $-78^{\circ} \mathrm{C}$.

b Volume ratio $(\mathrm{m} l / \mathrm{ml})$.

c Mol \% for the monomer. 
Measurement of polymer tacticity was made by the NMR method as reported previously. ${ }^{2,3}$ The typical NMR spectrum of each polymer is shown in Figure 2 and the calculated stereoregularities are listed in Table II.

In Table III, tacticity of the poly(GMA) is shown as a function of monomer concentration.

\section{DISCUSSION}

In the present study, the tacticity of the polymer obtained in the anionic polymerization of various methacrylic esters in toluene was found to be affected by the kind of esters and initiators used. Among the esters used, the ester which had a hetero atom in the alkyl group gave a polymer of lower isotacticity. This fact suggested the presence of an interaction of the hetero atom, as well as the anion of growing chain, with a counter cation. As a possible mode of interaction, coordination of the hetero atom as a Lewis base with the cation would be reasonable.

On the basis of the considerations described

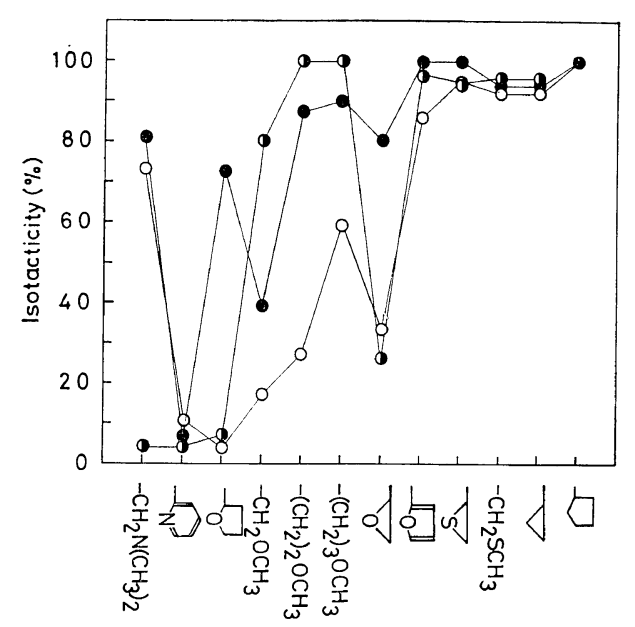

Figure 3. Relation between the isotacticity of the polymer and the structure of the monomer unit, which is shown on abscissa as a form of $\mathrm{R}$ in

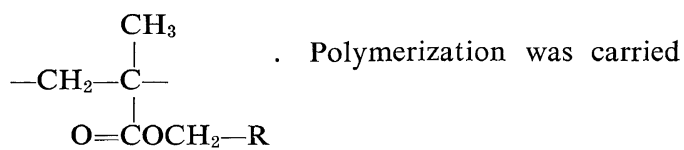

out in toluene at $-78^{\circ} \mathrm{C}$. Initiators: $\bigcirc, n$ - $\mathrm{BuLi}$; ๑, $\mathrm{LiAlH}_{4} ; i$-BuMgBr . above, the results were arranged as in Figure 3. In Figure 3, methacrylic esters were placed on the abscissa in the order of Lewis basicity of the hetero atom in the alkyl group, and the isotacticity of the polymer obtained was plotted on the vertical axis. Lewis basicity of the hetero atom was inferred from values obtained by Kagiya et al. ${ }^{12}$ The compounds which contain ether groups were placed in the order of the isotacticity of the polymer produced by $n-\mathrm{BuLi}$ because of the lack of detailed data on the basicity of ether.

As shown in Figure 3, the bulkiness of the alkyl group seemed to have almost no influence on the isotacticity of the polymer. However, the influence of the hetero atom was clearly observed.

If the interaction of the hetero atom was derived from its Lewis basicity, the compound which contains the more basic hetero atom could be expected to greatly influence the isotacticity of the polymer obtained. Actually, in the polymerization of MAMA using $i-\mathrm{BuMgBr}$ as initiator, the isotacticity of the polymer obtained was significantly suppressed. MAMA contains a tertiary nitrogen atom and is the strongest base among the compounds used. On the other hand, the polymerization of this monomer initiated by $n$-BuLi and $\mathrm{LiAlH}_{4}$ gave quite different results; the isotacticities of the polymer obtained were $72 \%$ and $82 \%$, respective1y. In these cases, it may be considered that the stereospecificity of polymerization was little influenced by the presence of the nitrogen atom. It is well known that the basicity of Lewis base such as tertiary amine against Lewis acid such as trialkylboron is altered by the steric hindrance, F-strain. Therefore, the slight coordination of the tertiary amine in the pendant alkyl group with the counter cation may be interpreted by some such cause as F-strain. If so, the coordination of the nitrogen atom is sterically hindered by the counter cations derived from $n$ BuLi and $\mathrm{LiAlH}_{4}$ but not by those from $i$ $\mathrm{BuMgBr}$, and the difference may be attributed to the type and/or degree of association of the initiators.

As is shown in Figure 3, the tetrahydrofurfuryl group gave a big influence to the isotacticity 
when in the alkyl group. However, when a small amount of THF was added to the polymerization system of methacrylic ester containing no hetero atom in the alkyl group, it was observed that THF had had no effect-as shown in Table II, No. 50 and 51. This result showed that the hetero atom which affects the stereopecificity of polymerization in toluene must be in a monomer or a polymer.

Further experiments in the polymerization of GMA by $\mathrm{LiAlH}_{4}$, where the monomer concentration is changed over a wide range may, at least in these experimental condition, support the result mentioned above. As is shown in Table III, no appreciable change in isotacticity was observed from the changes in monomer concentration which affect the polarity of the polymerization system, except in the case of solvent/monomer $=1$.

In most of the monomers used, the hetero atom in the alkyl group was placed in the $\beta$ position from ester oxygen. From such a structure, a strong interaction of the hetero atom in the ultimate monomer unit to the counter cation could be expected because a common-sized ring including counter cation, a growing chain end and a hetero atom could be formed as shown in the next figure, where $\mathrm{X}$ refers to the hetero atom.<smiles>CCC1(C)[Al]C2OCC[Y1]21</smiles>

An experiment carried out by changing the number of carbon atoms between the hetero atom and ester oxygen resulted in an increase in isotacticity according to the increase of carbon numbers as shown in Table II, Nos. 1-4 and 39-44. The result indicated that the larger the ring size the smaller the interaction of the hetero atom to the counter ion.

Concerning the interaction between acid and base, the concept of "hard and soft" proposed by Ahrland et al. ${ }^{13}$ and extended by Pearson ${ }^{14}$ was known to play an important role. Counter cations used in the present study, $\mathrm{Li}^{+}$and $\mathrm{Mg}^{++}$, belong to hard metal. The strength of the coordination of hard metal with group VIa atoms is shown to decrease in the order $\mathrm{O} \gg \mathrm{S}$ $>\mathrm{Se}>\mathrm{Te}$. If soft metal is used as a counter ion, coordination strength may be in the opposite order, and the result would give a different figure from that obtained by using hard metal as a cation. As shown in Table II, Nos. 18 and 24 , the isotacticity of poly(GMA) increased and that of poly(ETMA) decreased when using $\mathrm{SrZnEt}_{4}$ as an initiator, compared with the results obtained by using $n-\mathrm{BuLi}$ or $i-\mathrm{BuMgBr}$.

The presence of a compound with strong basicity in the neighborhood of a counter cation will also release the interaction of the growing chain end to the cation. Some experiments were carried out in THF as solvent.

Figure 4 shows the result obtained from polymerization in toluene, and Figure 5 shows that obtained using THF. The formation of syndiotactic poly(methyl methacrylate) by anionic polymerization in THF is well known, and this is explained by chain growth through the freeanionic mechanism. In the present study also the formation of syndiotacticity-rich polymers from all the monomers except GMA will be interpreted by the free-anionic mechanism.

GMA behaved in a curious manner. The

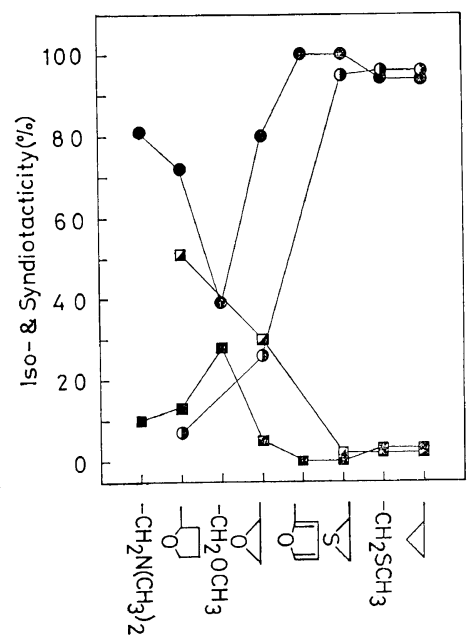

Figure 4. The isotacticity $\left(-, \mathrm{LiAlH}_{4} ; \mathrm{C}, i\right.$ $\mathrm{BuMgBr})$ and the syndiotacticity $\left(\mathbf{\square}, \mathrm{LiAlH}_{4} ; \mathbf{A}\right.$, $i-\mathrm{BuMgBr}$ ) of the polymer obtained in toluene. On the abscissa, the monomer structures are presented in the same manner as shown in Figure 3. 


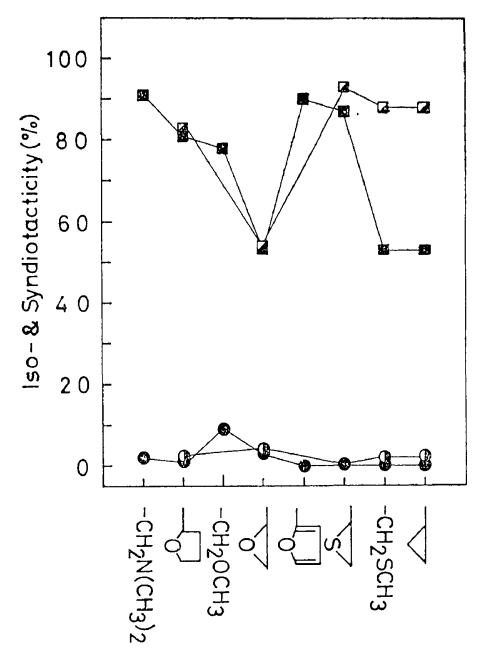

Figure 5. The isotacticity ( $\mathrm{LiAlH}_{4} ; \quad i$ -

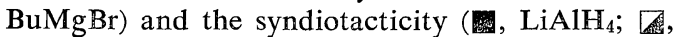
$i$-BuMgBr) of the polymer obtained in THF. On the abscissa, the monomer structures are presented in the same manner as shown in Figure 3.

isotacticity of the GMA polymer obtained in toluene was lower than that of poly(methacrylic ester), which contained ether oxygen, in spite of the smaller basicity of epoxy oxygen than that of ether oxygen. On the other hand, the syndiotacticity of poly(GMA) obtained in THF was also at a low level. These facts indicate that the epoxy oxygen played a special role in the process.

\section{EXPERIMENTAL}

\section{Solvents and Initiators}

Toluene and THF were purified and dried by the usual method.

$n$-BuLi in hexane used was commercially available and $\mathrm{LiAlH}_{4}$ was used in the same fashion as reported by Tsuruta et al.$^{4} i$-BuMgBr was prepared in diethyl ether by the usual method. Strontium zinc tetraethyl was prepared from metallic strontium and diethylzinc following the reported method. ${ }^{5}$ The concentration of $n$-BuLi in hexane was measured by the double titration method ${ }^{15}$ and the concentration of the diethyl ether solution of $\mathrm{LiAlH}_{4}$ and the Grignard reagent were estimated by iodometry. ${ }^{16}$ The EDTA-chelate titration method was used to determine the concentration of $\mathrm{SrZnEt}_{4}$.

\section{Monomers}

Methacrylic esters were prepared by the following procedure. Identification and confirmation of the purity of the monomers were made by IR and NMR spectroscopy.

Table IV. Preparations of monomers

\begin{tabular}{|c|c|c|c|c|c|}
\hline Monomera & Abbreviation & $\begin{array}{c}\text { Acid } \\
\text { acceptor }\end{array}$ & Solvent & $\begin{array}{l}\text { Vieldd } \\
(\%)\end{array}$ & $\mathrm{Bp}\left({ }^{\circ} \mathrm{C}(\mathrm{mm})\right)$ \\
\hline $\mathrm{N}, \mathrm{N}$-Dimethylaminoethyl methacrylate & MAMA & $\mathrm{Et}_{3} \mathrm{~N}$ & $\mathrm{Et}_{2} \mathrm{O}$ & 32 & $63.5(9)$ \\
\hline 2-Pyridylmethyl methacrylate & PMMA & $\mathrm{Et}_{3} \mathrm{~N}$ & $\mathrm{Et}_{2} \mathrm{O}$ & 32 & $86.0(2.5)$ \\
\hline Tetrahydrofurfuryl methacrylate & THFMA & - & - & 62 & $52.0(2)$ \\
\hline 2-Methoxyethyl methacrylate & MOMA & $\mathrm{Et}_{3} \mathrm{~N}$ & $\mathrm{Et}_{2} \mathrm{O}$ & 31 & $65.0-66.0(9)$ \\
\hline 3-Methoxypropyl methacrylate & MPMA & Py & $\mathrm{Et}_{2} \mathrm{O}$ & 46 & $61.0-62.0(7)$ \\
\hline 4-Methoxybutyl methacrylate & MBMA & Py & $\mathrm{Et}_{2} \mathrm{O}$ & 38 & $69.5-70.0(4.5)$ \\
\hline Glycidyl methacrylate*f & GMA & - & - & - & $49.0(2)$ \\
\hline Furfuryl methacrylate & FMA & $\mathrm{Et}_{3} \mathrm{~N}$ & $\mathrm{Et}_{2} \mathrm{O}$ & 89 & $65.0(2)$ \\
\hline 2, 3-Epithiopropyl methacrylate* & ETMA & - & $\mathrm{EtOH}-\mathrm{H}_{2} \mathrm{O}$ & $26^{\ominus}$ & $57.0(1)$ \\
\hline 2-Methylthioethyl methacrylate & MTMA & $\mathrm{Et}_{3} \mathrm{~N}$ & Benzene & 84 & $62.5(2)$ \\
\hline Cyclopropylmethyl methacrylate & CPrMA & $\mathrm{Et}_{3} \mathrm{~N}$ & $\mathrm{Et}_{2} \mathrm{O}$ & 66 & $50.2-50.5(7)$ \\
\hline Cyclopentylmethyl methacrylate & CPeMA & $\mathrm{Et}_{3} \mathrm{~N}$ & $\mathrm{Et}_{2} \mathrm{O}$ & 72 & $62.0(2)$ \\
\hline
\end{tabular}

a All monomers except those marked * are new compounds.

b $\mathrm{Et}_{3} \mathrm{~N}$ and $\mathrm{Py}$ refer to triethylamine and pyridine, respectively.

c $\mathrm{Et}_{2} \mathrm{O}$ and $\mathrm{EtOH}$ refer to diethyl ether and ethanol, respectively.

d Yield of the monomer on the basis of the alcohol commenced with.

e Yield of the monomer on the basis of GMA.

f Commercially available GMA was used. 
(1) Equimolar amounts of methacryloyl chloride and the corresponding alcohol were mixed in diethyl ether or in benzene in the presence of triethylamine or pyridine at room temperature, and the mixture was allowed to stand for one hour. The reaction mixture was washed with water and dried over sodium sulfate. After the removal of the solvent by distillation, the residual oil was distilled under reduced pressure. Yields and boiling points of the methacrylates obtained are summarized in Table IV.

(2) A certain amount of tetrahydrofurfuryl alcohol, a three-times excess amount of methyl methacrylate, $p$-toluenesulfonic acid as catalyst for the ester exchange reaction, and cupric chloride as an inhibitor for the polymerization reaction were mixed and heated at $60^{\circ} \mathrm{C}$ for five hours. During the course of the reaction methanol and methacrylic acid produced were continuously distilled off from the reaction vessel. The residual mixture was subjected to fractional distillation under reduced pressure to give tetrahydrofurfuryl methacrylate. The result is also described in Table IV.

( 3 ) 2,3-Epithiopropyl methacrylate was prepared from GMA and thiourea according to the method of Rogers. ${ }^{17}$

$$
\begin{aligned}
& \mathrm{CH}_{2}=\mathrm{C}-\mathrm{CH}_{3} \\
& \mathrm{O}=\stackrel{\mathrm{COCH}_{2}}{\mathrm{CH}-\mathrm{CH}_{2}}+\left(\mathrm{NH}_{2}\right)_{2} \mathrm{C}=\mathrm{S} \longrightarrow \\
& \mathrm{CH}_{2}=\mathrm{C}-\mathrm{CH}_{3}
\end{aligned}
$$

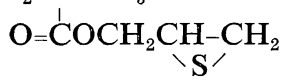

The result is listed in Table IV.

\section{Alcohols Used in the Preparation of Monomers 2-Methylthioethanol}

A certain amount of ethylene chlorohydrin was mixed with a $20 \%$ aqueous solution of an excess amount of the sodium salt of methyl mercaptan at $30^{\circ} \mathrm{C}$ for one hour. The reaction product was extracted with benzene, and subjected to fractional distillation to give a liquid: bp $68.0-68.8^{\circ} \mathrm{C}(12 \mathrm{~mm})$; yield $8.2 \mathrm{~g}(17.8 \%)$.

\section{3-Methoxypropanol}

Monosodium trimethylene glycol was prepared by the reaction of a certain amount of sodium and a three-times excess amount of trimethylene glycol. To the resultant mixture was added methyl iodide at $0^{\circ} \mathrm{C}$, and the reaction mixture was allowed to stand at room temperature for 3 hours. The reaction mixture was fractionated after separating sodium iodide by filtration to give 3-methyl propanol: bp $146-147^{\circ} \mathrm{C}$; yield $17.1 \mathrm{~g}$ (19\% based on sodium metal used).

\section{4-Methoxybutanol}

4-Methoxybutanol was prepared by the same procedure as described for 3-methoxypropanol from tetramethylene glycol.

\section{Cyclopropylcarbinol}

Cyclopropylcarbinol was prepared from trimethylene glycol via 3-chlorobutyronitrile, cyclopropanecarboxylic acid, as shown in the following equation. Boiling point of the product was $123-124^{\circ} \mathrm{C}^{18-20}$

$$
\begin{aligned}
& \mathrm{HO}\left(\mathrm{CH}_{2}\right)_{3} \mathrm{OH} \stackrel{\text { dry HCl}}{\longrightarrow} \mathrm{Cl}\left(\mathrm{CH}_{2}\right)_{3} \mathrm{OH} \stackrel{\mathrm{PBr}_{3}}{\longrightarrow} \\
& \mathrm{Cl}\left(\mathrm{CH}_{2}\right)_{3} \mathrm{Br} \frac{\mathrm{KCN}}{\mathrm{EtOH}-\mathrm{H}_{2} \mathrm{O}} \rightarrow \mathrm{Cl}\left(\mathrm{CH}_{2}\right)_{3} \mathrm{CN} \stackrel{\mathrm{NaOH}}{\rightarrow} \\
& \underset{\mathrm{CH}_{2}}{\mathrm{CH}_{2}-\mathrm{CHCOOH}} \frac{\mathrm{LiAlH}_{4}}{\mathrm{Et}_{2} \mathrm{O}} \rightarrow \underset{\mathrm{CH}_{2}}{\mathrm{CH}_{2}-\mathrm{CHCH}_{2} \mathrm{OH}}
\end{aligned}
$$

\section{Cyclopentylcarbinol}

Cyclopentylcarbinol was prepared from cyclohexanone as shown below. The overall yield of cyclopentylcarbinol was $33 \%$ on the basis of the quantity of cyclohexanone used to begin with. Its boiling point was $73-75.5^{\circ} \mathrm{C}(21 \mathrm{~mm})$.

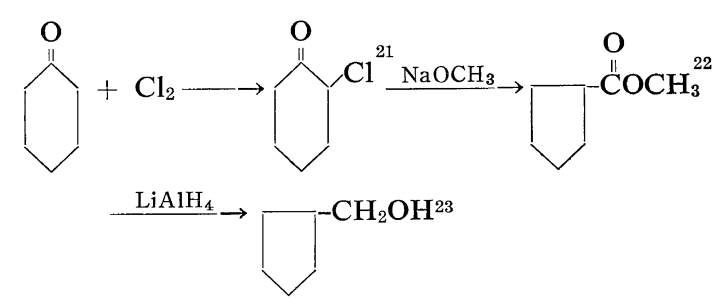

\section{Polymerization}

All the monomers were purified sufficiently by repeated distillation over calcium hydride immediately before polymerization.

Into a glass ampoule with a side-neck attached to a vacuum line, purified monomer was added by hypodermic syringe under a stream of nitrogen. The ampoule was then cooled to the temperature of liquid nitrogen and evacuated. Solvent was distilled into the ampoule by the trap-totrap method. Finally the initiator solution was added by means of hypodermic syringe under a 
stream of nitrogen, to the mixture of solvent and monomer, which had been cooled to the temperature of liquid nitrogen. The ampoule was again evacuated and then cut off from the vacuum line and put in a Dry Ice-methanol bath at $-78^{\circ} \mathrm{C}$.

After the completion of the reaction, the polymer precipitated by pouring the reaction mixture into an excess of methanol was purified by reprecipitation with benzene-methanol. In some cases, the polymer was isolated by freezedrying from a dioxane solution.

\section{NMR Spectroscopy}

NMR spectra of polymers were measured at $60^{\circ} \mathrm{C}$ in a $10-\%$ chloroform solution, using Varian HA-100, A-60 A, and Japan Electron Optics Laboratory $3 \mathrm{H}-60$ and C-60 spectrometers. Tetramethylsilane was used as the internal standard. Relative amounts of isotactic, heterotactic, and syndiotactic configurations in the polymer were calculated from the relative height of each peak ascribed to the $\alpha$-methyl proton according to the base-line method.

Acknowledgement. The authors are very grateful to Chisso Corporation and to Asahi Chemical Industry Co. for NMR studies, and to Nippon Oils \& Fats Co. Ltd. for supplying GMA.

\section{REFERENCES}

1. Y. Iwakura, T. Kurosaki, N. Ariga, and T. Ito, Makromol. Chem., 97, 128 (1966).

2. Y. Iwakura, F. Toda, T. Ito, and K. Aoshima, ibid., 104, 26 (1967).

3. Y. Iwakura, F. Toda, T. Ito, and K. Aoshima, J. Polym. Sci., Part B, 5, 29 (1967).

4. T. Tsuruta, T. Makimoto, and Y. Nakayama, Makromol. Chem., 90, 12 (1966).

5. T. Tsuruta, T. Makimoto, and H. Kanai, $J$. Macromol. Chem., 1, 31 (1966).

6. D. J. Cram and K. R. Kopecky, J. Amer.
Chem. Soc., 81, 2748 (1959); D. J. Cram, J. Chem. Educ., 37, 317 (1960).

7. C. E. H. Bawn and A. Ledwith, Quart. Rev. (London), 16, 361 (1962).

8. W. E. Goode, F. H. Owens, and W. L. Myers, J. Polym. Sci., 47, 75 (1960).

9. D. L. Glusker, E. Stiles, and B. Yoncoskie, ibid., 49, 297 (1961).

10. J. Furukawa, Polymer, 3, 487 (1962).

11. A. Nishioka, H. Watanabe, K. Abe, and $Y$. Sono, J. Polym. Sci., 48, 241 (1960).

12. T. Kagiya, Y. Sumida, and T. Inoue, Bull. Chem. Soc. Japan, 41, 767 (1968).

13. S. Ahrland, J. Chatt, and N. R. Davies, Quart. Rev. (London), 12, 265 (1958).

14. R. G. Pearson, J. Amer. Chem. Soc., 85, 3533 (1963).

15. H. Gilman and J. W. Morton Jr., "Organic Reactions," Vol. 8, R. Adams, Editor-in-Chief, John Wiley \& Sons, Inc., New York, N. Y., 1954, p 285.

16. H. Felkin, Bull. Soc. Chim. France, 18, 347 (1951).

17. F. E. Rogers, J. Polym. Sci., Part A, 3, 2701 (1965).

18. C. F. H. Allen, “Organic Synthesis," Coll. Vol. I, H. Gilman and A. H. Blatt, Editorin-Chief, John Wiley \& Sons, Inc., New York, N. Y., 1964, p 156.

19. C. M. McCloskey and G.H. Coleman, "Organic Synthesis, Coll. Vol. HI, E. C. Horning, Editor-in-Chief, John Wiley \& Sons, Inc., New York, N. Y., 1965, p 221.

20. J. D. Roberts and R. H. Mazur, J. Amer. Chem. Soc., 73, 2509 (1951).

21. M. S. Newman, M. D. Farbman, and $H$. Hipsher, "Organic Synthesis," Coll. Vol. III, E. C. Horning, Editor-in-Chief, John Wiley \& Sons, Inc., New York, N. Y., 1965, p 188.

22. D. W. Goheen and W. R. Vaughan, "Organic Synthesis, Vol. 39, M. Tishler, Editor-in-Chief, John Wiley \& Sons. Inc., New York, N. Y., 1959, p 37.

23. V. N. Ipatieff, W. W. Thompson, and H. Pines, J. Amer. Chem. Soc., 73, 553 (1951). 